\title{
Genital examination under ketamine sedation in cases of suspected sexual abuse
}

\author{
Michael D Harari, Dvorah Netzer
}

\begin{abstract}
Sedation for genital examination in suspected sexual abuse is seldom discussed. The cases are presented of three children in whom genital examination was facilitated by ketamine sedation; these children could not be examined under any other circumstances. Ketamine provides safe, effective sedation, analgesia, and amnesia in an ambulatory setting. Its use should be considered in selected patients.

(Arch Dis Child 1994; 70: 197-199)
\end{abstract}

Paediatricians working in child protection services increasingly perform genital examinations of victims of suspected child sexual abuse. Rarely the examination is highly traumatic and is therefore abandoned. We report the cases of three children in whom ketamine sedation facilitated such an examination.

\section{Case reports}

CASE 1

A 4 year old girl presented with vaginal bleeding ostensibly having fallen in the path of an approaching car that day. A general physical examination showed no abnormalities. Attempted genital examination by several gynaecologists caused the child great distress. The suboptimal examination was described as normal. The child protection team was then notified. Questioning of the mother and child by our social worker showed no evidence of child sexual abuse. After securing maternal consent, $1.5 \mathrm{mg} / \mathrm{kg}$ ketamine and $0.01 \mathrm{mg} / \mathrm{kg}$ atropine were administered intravenously over 90 seconds, with the child breathing spontaneously in room air. Her blood pressure increased from $100 / 70$ to $140 / 90 \mathrm{~mm} \mathrm{Hg}$. Oxygen saturation, measured by continuous pulse oximetry, remained unchanged at $98 \%$. The examination lasted three minutes. Thirty minutes later, after no hypnopompic irritability, the child was alert and had eaten. Her hymenal diameter was $<0.5 \mathrm{~cm}$ and regular. A $2 \mathrm{~cm}$ ragged tear $1 \mathrm{~mm}$ posterior to and parallel with the left side of the posterior fourchette was found, with no other genital injury. This was thought to be unusual for road trauma. After several home visits by a social worker the child reported sexual interference by a cousin.

\section{CASE 2}

An 8 year old girl was admitted in a confused and uncooperative state to our intensive care unit with staphylococcal septicaemia and a history of several days purulent vaginal discharge. Genital examination was considered essential to exclude the presence of a foreign body or child sexual abuse. After securing maternal consent, ketamine and atropine were administered as for patient 1 . The procedure lasted three minutes and was uneventful apart from mild transient hypertonia. Genital examination was unremarkable and vaginal cultures were taken. She awoke gradually and peacefully over 45 minutes. The following day, much improved, she had no recollection of the examination nor of hallucinations.

\section{CASE 3}

An 8 year old girl presented with vaginal warts. A year earlier digital warts had resolved spontaneously. Mother and child discounted the possibility of child sexual abuse. The girl was profoundly embarrassed at the prospect of genital examination, but agreed to an examination under sedation. Ketamine and atropine were given as for patient 1 . Recovery was normal and complete within 45 minutes, with complete amnesia of the procedure. She described bizzare though not distressing hypnopompic thoughts. The only anogenital findings were two labial warts, presumably due to self infection.

\section{Discussion}

Genital examination is important, though not pre-eminent, in cases of suspected child sexual abuse. With a gentle and sensitive explanation it is usually conducted in a relaxed fashion. ${ }^{1}$ Even in centres with vast experience, however, it may be traumatic. Of 337 children diagnosed by Hobbs and Wynne as sexually abused, ${ }^{1} 21(6 \%)$ presented 'serious difficulties' in examination, ranging from lack of cooperation to refusal. In addition, $41(12 \%)$ children were anxious or frightened, 49 (15\%) were passive or mute, and six $(2 \%)$ were hostile.

Such difficulties may arise from embarrassment, fear of pain, or threatening surroundings (colposcopy, cameras, strangers), as well as terror or fear if the child has indeed been abused. In addition, distressing diagnostic procedures such as speculum examination or urinary catheterisation ${ }^{2}$ may occasionally be required.

Faced with serious difficulties the genital examination should be abandoned, ${ }^{3}$ though positive physical findings are helpful in 
corroborating the child's account and in providing evidence in criminal proceedings which require a high standard of proof. A deferred examination may miss rapidly resolving anogenital signs. ${ }^{4}$

A seldom discussed alternative is sedation of an otherwise unexaminable child. Although this makes assessing the child's response to the examination impossible, it is probably irrelevant to the diagnosis if a good interview and examination are carried out. ${ }^{5}$

Ketamine hydrochloride, a sedative, amnesic, and analgesic drug, produces dissociative anaesthesia, a trance-like cataleptic state. It has been used extensively outside the operating theatre for burn ward procedures, taking bone marrow biopsy samples, dental work, and other distressing procedures. ${ }^{6}$ Respiration and protective airway reflexes are maintained, ${ }^{6}$ rendering assisted ventilation or endotracheal intubation unnecessary. Supplementary oxygen is rarely needed, but should be available. ${ }^{6}$ Ketamine temporarily increases blood and intracerebral pressures and rarely causes laryngospasm. The recommended dose of $1-2 \mathrm{mg} / \mathrm{kg}$ intravenously or 4 $\mathrm{mg} / \mathrm{kg}$ intramuscularly, with $0.1 \mathrm{mg} / \mathrm{kg}$ atropine as an antisialagogue provides anaesthesia for several minutes. Previous fasting is desirable, but not obligatory, as gag and coughing reflexes are preserved. ${ }^{6}$ The hypnopompic hallucinations and irritability common in adults are rare in children and respond well to diazepam. ${ }^{6}$ Transient diplopia and nystagmus are common. Amnesia of the procedure is universal.

In cases of suspected child sexual abuse, genital examination under ketamine sedation is not a substitute for a properly conducted examination of an informed, relaxed, participating, conscious child by a skilled examiner. If these conditions cannot be met, however, it may be considered. It is safe, effective, and can be administered in an ambulatory setting if resuscitation equipment and oxygen are available. $^{6}$

1 Hobbs CJ, Wynne JM. Child sexual abuse - an increasing rate of diagnosis. Lancet 1987; ii: 837-41.

2 Johnson CF. Prolapse of urethra: confusion of clinical and anatomic characteristics with sexual abuse. Pediatrics 1991, 87: 722-5.

3 Bamford F, Roberts R. ABC of child abuse: child sexua abuse - I. BMF 1989; 299: 312-3.

4 Finkel MA. Anogenital trauma in sexually abused children Pediatrics 1989; 84: 317 .

5 Dubowitz $\mathrm{H}$, Black $M$, Harrington D. The diagnosis of child sexual abuse. Am $\mathcal{F}$ Dis Child 1992; 146: 688-93.

6 Green SM, Johnson NE. Ketamine sedation for pediatric procedures: part 2, review and implications. Ann Emerg Med 1990; 19: 1033-46.

\section{Commentary}

Examination of children suspected of being sexually abused is an increasing part of paediatric practice, ${ }^{1}$ and all paediatricians must be competent to undertake the anal and genital part of this examination. The examination is a vitally important part of any assessment where child sexual abuse is suspected and should be undertaken by trained doctors.

Anxieties can arise for a number of reasons. (1) Work in child sexual abuse can be difficult and time consuming. (2) Cases may be controversial when parents vigorously dispute that abuse has happened. (3) Doctors may feel uncertain of their knowledge of normal and abnormal findings, although recent publications should help in writing reports and presenting evidence at case conferences or courts. $^{23}$

The examination itself, however, may raise specific worries for professionals, carers, and child. Concern that the examination itself may be interpreted by the child as further abuse needs to be discussed. Some of these concerns may be appreciated by the doctor who may feel inhibited not wishing to cause further upset to the child or adult. Misunderstanding can add to the difficulties.

Parents and others advising them may think that the procedure will involve an internal examination whereas inspection is now usual practice. Explanation and preparation (for example by parent, social worker, doctor, or nurse) will reassure.

Most children will have been upset, frightened, or confused by the abuse and may bring those feelings to the examination. However, children also recognise when people are there to help them and for many the medical examination will reassure that someone has noticed and heard their distress.

What of those children who either refuse or are too frightened to cooperate? Every doctor (even the most experienced and skilled) sees a few of these. It is worth asking a few questions in this situation: Can the child tell of any specific worries? Who will accompany the child? (Let the child decide who they would like with them.) Would a female or male doctor be more appropriate? What has the child been told? (For example, it will hurt, don't cooperate, you don't need to have this done if you don't want.) Has the child been adequately prepared? Is the child old enough to give consent? ${ }^{4}$ Is the child being left to make the decision on their own and therefore left with the responsibility for their own protection?It goes without saying that a doctor should never force an examination against a child's wishes. Very often additional time can be sought for work with the child and another appointment made when the child has had further time to think.

So when is it reasonable to turn to anaesthesia or sedation? In practice there are very few situations but where the child is frightened, cooperative but unable to relax sufficiently and there is some special urgency, it may be indicated. Rarely there are major injuries which require assessment and surgical repair and anaesthesia is then usually needed.

It is important to remember that some children are drugged before abuse and others feign sleep during the abuse. One should be sensitive to what 'putting you to sleep' may mean to the child. Paediatricians must stress the positive value of a skilled examination in child sexual abuse for the protection and support of the child and encourage and reassure adults and children alike. 